\title{
ANALYTICAL STRATEGY TO INVESTIGATE 3,4-METHYLENEDIOXYPYROVALERONE (MDPV) METABOLITES IN CONSUMERS' URINE BY HIGH RESOLUTION MASS SPECTROMETRY
}

María Ibáñez ${ }^{1 *}$, Óscar J. Pozo ${ }^{2}$, Juan V Sancho ${ }^{1}$, Teresa Orengo ${ }^{3}$, Gonzalo Haro ${ }^{4,5}$, Félix Hernández ${ }^{1}$

${ }^{1}$ Research Institute for Pesticides and Water, University Jaume I, Avda. SosBaynat, E-12071 Castellón, Spain.

${ }^{2}$ Bioanalysis Research Group, IMIM, Hospital del Mar Medical Research Institute, Doctor Aiguader 88, 08003 Barcelona, Spain

${ }^{3}$ Addictions Treatment Unit Grao-Clínico, Valencia, Spain

${ }^{4}$ School of Medicine, University CEU-Cardenal Herrera, Castellón

${ }^{5}$ Psychiatry Department, Consorcio Hospitalario Provincial de Castellón

* Corresponding author ibanezm@uji.es, Tel +34 964 387339, Fax +34 964387368 


\begin{abstract}
The potential of high resolution mass spectrometry (HRMS) for the investigation of human in vivo metabolism of 3,4-methylenedioxypyrovalerone (MDPV) using urine collected from a consumer (this is, in non-controlled experiments) has been investigated. As a control sample was not available, the common approach based on the comparison of a control/blank sample and samples collected after drug intake could not be used. Alternatively, an investigation based on common fragmentation pathways was applied, assuming that most metabolites share some fragments with the parent drug. An extension of this approach was also applied based on the fragmentation pathway of those metabolites identified in urine samples in the first step. The use of $\mathrm{MS}^{\mathrm{E}}$ experiments (sequential acquisition of mass spectra at low and high collision energy) has been crucial to this aim as it allowed promoting fragmentation in the collision cell without any previous precursor ion selection. MDPV belongs to the group of new psychoactive substances (NPS), being known as the "cannibal drug". This substance is being more and more abused and associated with dangerous side effects. The human metabolites (both phase I and phase II) were detected and tentatively identified by accurate-mass full-spectrum measurements using ultra-high performance liquid chromatography coupled to hybrid quadrupole time of flight mass spectrometry (UHPLC-QTOF MS). Following this strategy, up to 10 phase I metabolites, together with some glucuronides and sulphates, were detected and tentative structures were proposed. Several compounds identified in this work have not been previously reported in the literature.
\end{abstract}

Keywords: new psychoactive substances, 3,4-methylenedioxypyrovalerone, metabolism, urine, liquid chromatography, time-of-flight mass spectrometry. 


\section{INTRODUCTION}

The recreational drug market has changed notably in recent years to incorporate a range of new psychoactive substances (NPS), collectively known as "legal highs" or "designer drugs". These are chemical analogues of illegally abused substances, usually devised to circumvent drug laws. Different reports have concluded that studies should be encouraged on the metabolism of NPS, as the unchanged forms may only be present in a low amount in human urine due to extensive metabolism [1-2]. That research would also help to select the most representative analytes for wastewater analysis in order to estimate the drug use, a recent approach known as sewage-based epidemiology [3].

Most metabolism studies are carried out under controlled conditions, and therefore both control/blank samples and samples collected after drug intake are available. This facilitates the comparison of their fullspectrum acquisition MS data using commercial spectral/chromatographic comparative software. However, in some cases, such as the investigation reported in this paper, no control sample is available as the urine is collected from real consumers of NPS.

In this work, urine from a 35 year-old man who self-reported to have taken 3,4methylenedioxypyrovalerone (MDPV) (see structure in Figure 1) was collected. MDPV is an analogue of pyrovalerone, a psycho stimulant that was used to treat lethargy and chronic fatigue in the 1970s, but was later withdrawn from the market because of problems with abuse and dependency [4-5]. In internet forums, MDPV is reported by users to be a potent psycho stimulant and psychedelic drug that is more active than methylphenidate when a mean dose of $10 \mathrm{mg}$ is used intranasal, oral or rectal administration. Different episodes of cannibalism have been recently associated to the consumption of this drug [6-7].

Ultra-high performance liquid chromatography coupled to high resolution mass spectrometry (UHPLCHRMS), specifically using a hybrid quadrupole-time of flight mass spectrometry (QTOF MS), has been used in this work for the investigation of human in vivo metabolites of this NPS in urine samples. The fact that no control sample was available complicated the study, and therefore an alternative strategy, based on common fragmentation pathway, was applied. This approach presumes a common fragmentation pathway for metabolites and the parent drug. Assuming that most metabolites share the same fragmentation pathway with the parent drug, specific narrow-window extracted ion chromatograms (nw-XICs) at the expected exact-mass $\mathrm{m} / \mathrm{z}$ fragments were obtained from high-energy full-spectrum TOF MS acquisitions. The occurrence of chromatographic peaks at different retention times than the parent drug alerts the 
investigator on the presence of potential drug metabolites. In this work, an extension of this approach has been applied, based not only on the fragmentation pathway of parent drug but also on that of the previously identified metabolites in the urine sample [8-9].

The use of $\mathrm{MS}^{\mathrm{E}}$ experiments (sequential acquisition of accurate mass data at low and high collision energy) was of great importance to ensure the success of this strategy, as it allows the fragmentation of compounds in the collision cell without any previous precursor ion selection. By applying low energy (LE), fragmentation is minimized and the information obtained normally corresponds to the parent molecule (commonly the (de)protonated molecule, but also adducts in some cases). However, at high energy (HE), fragmentation of the molecule is favoured, which is of much help in the elucidation process. So, both (de)protonated molecule and fragment ion data are available in a single acquisition without the need of selecting the precursor ion [10-11]. The resulting metabolites (both Phase I and Phase II) were detected and tentatively identified by accurate-mass full-spectrum measurements.

Some MDPV metabolites, elucidated during in-vitro incubations with human liver microsomes [12-13] and administration studies in rats' urine [12] have been afterwards detected in human urine [12]. This approach allows for the detection of a broad range of metabolites being either common metabolites between rats and humans or metabolites produced by human liver microsomes. In both methods, the resulting metabolites were analysed using gas chromatography/mass spectrometry as trimethylsilyl derivatives. The structure of the metabolites was further confirmed by accurate mass measurement using a LC-HR MS. In the last few years, some of the metabolites identified in the previous works [12-13] have been detected in human and rat plasma [14] or in urine of a patient who self-reported to have injected some doses of MDPV [15] by LC-HRMS(/MS). Paul et al [16] developed a LC-HRMS-QTOF method for the screening and semi-quantification of 62 compounds (including MDPV) in urine. Moreover, they identified a new hydrogenated metabolite of MDPV.

However, some specific human metabolites not produced by liver microsomes might remain unnoticed. Thus studies devoted to the direct study of metabolites in human urine are needed. Finally, Mardal et al. [1] tentatively identified 12 microbial biotransformation products after incubation of MDPV in wastewater for 10 days. No additional MDPV biotransformation products could be found after incubating in rat urine and faeces samples. 


\section{MATERIALS AND METHODS}

\subsection{Reagents and chemicals}

MDPV reference standard was acquired from Cayman Chemicals (Michigan, USA). HPLC-grade methanol $(\mathrm{MeOH})$, acetonitrile $(\mathrm{ACN})$, formic acid $(\mathrm{HCOOH})(>98 \%)$ and sodium hydroxide $(>99 \%)$ were purchased from ScharLab (Barcelona, Spain). . Leucine encephalin and $\beta$-glucuronidase type HP-2 from Helix pomatia $(\geq 100,000$ units $/ \mathrm{mL}$, containing also $\leq 7,500$ units $/ \mathrm{mL}$ sulfatase) were purchased from Sigma Aldrich (St. Louis, MO, USA). HPLC-grade water was obtained from deionized water passed through a Milli-Q water purification system (Millipore, Bedford, MA, USA).

\subsection{Instrumentation}

An Acquity ultra-performance liquid chromatography (UPLC) system (Waters, Milford, MA, USA) was interfaced to a QTOF mass spectrometer (QTOF Xevo G2, Waters Micromass, Manchester, UK) using an orthogonal Z-spray electrospray interface. The LC separation was performed using Acquity UPLC BEH C18 $1.7 \mu \mathrm{m}$ particle size analytical column of $100 \times 2.1 \mathrm{~mm}$ (from Waters), at a flow rate of $0.3 \mathrm{~mL} / \mathrm{min}$. The mobile phases used were $\mathrm{A}_{2} \mathrm{O}$ and $\mathrm{B} \mathrm{MeOH}$, both with $0.01 \%$ (v/v) $\mathrm{HCOOH}$. The proportion of $\mathrm{MeOH}$ was linearly increased as follows: $0 \mathrm{~min}, 10 \% ; 14 \mathrm{~min}, 90 \% ; 16 \mathrm{~min}, 90 \% ; 16.01 \mathrm{~min}, 10 \%$ and 18 min, 10\%. The injection volume was $20 \mu \mathrm{L}$. Nitrogen (Praxair, Valencia, Spain) was used as both the desolvation gas and the nebulising gas. The gas flow rate was set at $1000 \mathrm{~L} / \mathrm{h}$. The resolution of the TOF mass spectrometer was approximately 20,000 at full width half maximum at $\mathrm{m} / \mathrm{z} 556$. MS data were acquired over a $m / z$ range of 50-1000 in a scan time of $0.4 \mathrm{~s}$. The MCP detector potential was set to 3700 V. Capillary voltages of $0.7 \mathrm{kV}$ and $-2.0 \mathrm{kV}$ were used in positive and negative ionization modes, respectively. A cone voltage of $15 \mathrm{~V}$ was applied. The collision gas was argon (99.995\%, Praxair). The interface temperature was set to $600{ }^{\circ} \mathrm{C}$ and the source temperature to $130{ }^{\circ} \mathrm{C}$. The column temperature was set to $40^{\circ} \mathrm{C}$ and the samples to $5^{\circ} \mathrm{C}$.

For $\mathrm{MS}^{\mathrm{E}}$ experiments, two acquisition functions with different collision energies were created: the LE function with collision energy of $4 \mathrm{eV}$, and the $\mathrm{HE}$ function with a collision energy ramp ranging from 15 to $30 \mathrm{eV}$.

MS/MS experiments were also performed, using a cone voltage of $15 \mathrm{~V}$ and collision energies of 10, 15 and $20 \mathrm{eV}$. For phase II metabolites, and in those cases in which a single abundant product ion was 
obtained, a pseudo-MS ${ }^{3}$ experiment was performed by selecting as precursor ion the dominant in-source generated fragment at higher cone voltage $(30 \mathrm{~V})$ and acquiring the product ion scan of this in-source fragment.

Calibration of the mass-axis from $\mathrm{m} / \mathrm{z} 50$ to 1000 was conducted daily with a $1: 1$ mixture of $0.05 \mathrm{M}$ $\mathrm{NaOH} / 5 \%(\mathrm{v} / \mathrm{v}) \mathrm{HCOOH}$ diluted $(1: 25)$ with water/ACN $(20: 80 \mathrm{v} / \mathrm{v})$.

For automated accurate mass measurement, the lock-spray probe was employed, pumping leucine enkephalin $(10 \mathrm{mg} / \mathrm{L})$ in $\mathrm{ACN} /$ water $(50 / 50)$ at $0.1 \% \mathrm{HCOOH}$, at $20 \mu \mathrm{L} / \mathrm{min}$ through the lock-spray needle. The leucine enkephalin $[\mathrm{M}+\mathrm{H}]^{+}$ion $\left(\mathrm{m} / \mathrm{z}\right.$ 556.2771) for positive ionization mode, and $[\mathrm{M}-\mathrm{H}]^{-}$ion $(\mathrm{m} / \mathrm{z}$ 554.2615) for negative ionization, were used for recalibrating the mass axis and to ensure a robust accurate mass measurement over time.

The data station operating software was MassLynx version 4.1 (Waters).

\section{$\underline{2.3 \text { Samples }}$}

The patient was a 35-year old male, who was receiving treatment (valproic acid, paliperidone and amisulpride) since 2008 at Addictions Treatment Unit in Valencia (Spain). He has a history of cocainerelated disorder and substance-induced psychoses. One year ago, the patient replaced cocaine for consumption of legal highs (MDPV) acquired in a smart shop. Recently, he developed a manic episode and required hospitalization at a dual disorder unit in Castellón (Spain). After detoxification from legal highs, negative psychoses symptomatology persisted. The diagnosis was then changed from substanceinduced psychoses to schizoaffective disorder. For the metabolism study, urine sample from this patient with MDPV-related disorder was collected in a sterile bottle during hospitalization, which was stored at $18{ }^{\circ} \mathrm{C}$ until analysis. The study protocol was approved by the local ethical committee (Ref: DG NRI6 1424-10). The patient gave informed consent to the procedure.

For the determination of phase I metabolites, $1 \mathrm{~mL}$ of centrifuged urine was buffered with $50 \mu \mathrm{L}$ acetic acid/ammonium acetate ( $\mathrm{pH}$ 5.5). After being hydrolyzed overnight with 2000 units of $\beta$-D-glucuronidase (also containing sulfatase) at $37^{\circ} \mathrm{C}$ [17], $50 \mu \mathrm{L}$ of the hydrolyzed mixture were injected in the LC-QTOF MS system. 
For direct determination of phase II metabolites, $1 \mathrm{~mL}$ of urine previously centrifuged (12,000 r.p.m., 10 minutes), was two-fold diluted with Milli-Q water. After that, $50 \mu \mathrm{L}$ were directly injected in the LCQTOF MS system.

Additionally, the consumed legal high was also analyzed. For this purpose, 0.2 gr of the powder were extracted with acetone using ultrasounds. After that, the extract was 100-fold diluted with water and directly injected in the system.

\subsection{Data processing}

Acquisitions were performed in centroid, in both positive and negative ionisation mode. For all compounds detected, the accurate mass of protonated/deprotonated molecules was determined on the basis of averaged spectra obtained in the LE survey scan. Then, possible elemental compositions were calculated using the MassLynx elemental composition calculator with a maximum deviation of $2 \mathrm{mDa}$ from the measured accurate mass. The maximum and minimum parameters were restricted considering the elemental composition and structure of MDPV $\left(\mathrm{C}_{16} \mathrm{H}_{21} \mathrm{NO}_{3}\right)$ and the possibility of phase II metabolism, such as glucuronidation or sulphatation, as follows: C 0-25, H 0-40, N 0-4, O 0-10 and S $0-1$. The applied double-bond equivalent filter was set between -0.5 and 50 . To calculate the elemental composition of product ions, parameters settings were restricted as a function of the calculated elemental composition of the (de)protonated molecule, while for neutral losses no restrictions were applied. Additionally, the option "even-electrons ions only" was selected for the precursor ion, and "odd- and even-electrons ions" for the product ions. 


\section{RESULTS AND DISCUSSION}

\subsection{Mass spectrometric behaviour of MDPV}

Initially, an in-depth study of both the ionization and the fragmentation behavior of the parent drug is essential to obtain the origin and the structural information related with each valuable product ion. Due to the absence of acidic moieties, MDPV only showed ionization in positive mode with a prominent $[\mathrm{M}+\mathrm{H}]^{+}$ at $m / z$ 276.1590. Product ion scan experiments for MDPV produced a rich spectrum providing abundant structural information (Figure 1).

Product ions could be classified based on the structural information provided. Thus, the ions at $\mathrm{m} / \mathrm{z}$ 126.1277 and $m / z$ 84.0810 together with the neutral loss of $71.0721 \mathrm{Da}\left(\mathrm{C}_{4} \mathrm{H}_{9} \mathrm{~N}\right.$; ion at $\mathrm{m} / z$ 205.0859) were indicative of the pyrrolidine function. The neutral loss of $43.0543 \mathrm{Da}\left(\mathrm{C}_{3} \mathrm{H}_{7}\right.$; ion at $\mathrm{m} / z$ 233.1047) corresponded to the loss of the propyl chain. Additionally, the ions at $\mathrm{m} / \mathrm{z} 149.0233, \mathrm{~m} / \mathrm{z} 135.0440$ and $\mathrm{m} / \mathrm{z} 121.0293$ indicated the presence of the methylenedioxy group coupled to the catechol moiety. Finally, the abundant ion at $\mathrm{m} / \mathrm{z} 175.0753$ was explained after the loss of both pyrrolydine and methylendioxy groups and, therefore this ion can be associated with the skeleton of the MDPV.

\subsection{Analytical strategy for detecting MDPV metabolites without control sample}

The detection of MDPV metabolites was performed assuming that MDPV and metabolites share a common fragmentation pathway. Thus, MDPV metabolites would share some fragments with the parent drug at the HE function. Therefore, MDPV metabolites can be detected by extracting the $m / z$ of the MDPV product ions from the total ion current (TIC) chromatogram of the HE function. In our case, 8 nwXICs (0.02 Da mass window) corresponding to the $\mathrm{m} / \mathrm{z}$ of the main MDPV product ions were extracted from the TIC of the HE function in the hydrolyzed urine sample.

Every chromatographic peak with a retention time different than the parent drug was treated as a potential metabolite. The combined spectrum at the same retention time in the LE function allowed for establishing the accurate mass of the potential metabolite. Figure S.1 in Electronic supplementary Material shows the XICs for the 10 phase I metabolites detected. In this work, the mass accuracy obtained provided only one feasible formula for each metabolite considering the established mass error ( $2 \mathrm{mDa})$, except for metabolite M5, which provided two possibilities. The most coherent formula was found to be the one with lower mass deviation and was selected as molecular formula for the metabolite. 
Table 1 shows a summary of the detection of MDPV metabolites by using common fragments extracted from the HE function. Some of the selected ions (e.g. $\mathrm{m} / \mathrm{z}$ 149.0232, $\mathrm{m} / \mathrm{z}$ 135.0440) allowed for the detection of only one metabolite (M5) whereas three different metabolites were detected by the selection of the ion at $\mathrm{m} / \mathrm{z} 175.0752$ (corresponding to the MDPV skeleton). Only the extraction of the ion at $\mathrm{m} / \mathrm{z}$ 233.1047 did not reveal any metabolite.

Figure 2 shows the iterative workflow followed. No visible peaks were observed in the TIC of the hydrolised urine (Fig 2a). After applying the explained strategy performing the nw-XIC at $\mathrm{m} / \mathrm{z}$ 175.0752 in the HE function (Fig 2b) three chromatographic peaks were observed, corresponding to MDPV (at 5.5 min) but also to two possible metabolites (M1 at 2.75 and M2 at $4.55 \mathrm{~min}$ ). The HE spectra of both peaks were extracted (Fig 2c) as well as the LE spectra (Fig 2d), in order to known the accurate mass of both metabolites. When the nw-XIC was performed at $m / z, 278$ in the LE function (Fig 2e, bottom), an additional chromatographic peak was observed at $5.37 \mathrm{~min}$, surely related with a new metabolite isomeric to $\mathrm{M} 2$ but not sharing the fragment at $\mathrm{m} / \mathrm{z}$ 175. In fact, this peak corresponds to M8.

However, the use of common fragmentation pathway methodology presents some limitations when the metabolic reactions suffered by the parent drug shift the $\mathrm{m} / \mathrm{z}$ values of the product ions of the metabolite. This fact can be even more important when these reactions alter the fragmentation pathway. An alternative to circumvent this drawback is to perform an iterative approach extracting also additional fragment ions from previously detected metabolites. Therefore, this approach assumes that a metabolite can share more structural characteristics with other metabolites than with its own parent drug. That was the case of M4 which exhibited a product ion at $\mathrm{m} / \mathrm{z}, 98.0602$ absent in the product ion spectrum of the parent molecule. Thus, a new nw-XIC at this $m / z$ was performed from the TIC acquired by high energy CID-TOF MS. This allowed the detection of M3, M6 and M7, that otherwise would have been lost (see Table 1).

The application of the proposed strategy, based on acquisition in UHPLC-QTOF MS in MS ${ }^{\mathrm{E}}$ mode and posterior data processing based on common fragmentation pathway, to the hydrolyzed extract of the urine collected from a patient with MDPV-related disorder allowed for the detection of the parent drug and 10 phase I metabolites.

\subsection{MDPV phase I metabolites}


The accurate mass of each detected metabolite was studied in order to determine its molecular formula. The ionization of the metabolite in negative ionization mode was shown as indicative of the presence of acidic moieties (carboxylic or phenolic groups). Finally, QTOF MS/MS experiments were performed and the results compared with the behaviour of MDPV. Based on all this information, a putative structure for each metabolite was established.

\section{Metabolite M1}

M1 showed a $[\mathrm{M}+\mathrm{H}]^{+}$at $m / z, 264.1593$ which corresponds to $\mathrm{C}_{15} \mathrm{H}_{22} \mathrm{NO}_{3}$ (Table 2), i.e. a carbon atom less than MDPV. The product ion scan in positive mode (Table 3 and see Figure S.2 in Electronic Supplementary Material) was similar to the one obtained for MDPV. The presence of the ions at $\mathrm{m} / \mathrm{z}$ $126.1278, \mathrm{~m} / \mathrm{z} 84.0809$ and the neutral loss of $71.0732 \mathrm{Da}$ (ion at $\mathrm{m} / \mathrm{z}, 193.0861$ ) indicated an unaltered pyrrolidine ring. The neutral loss of $43.0546 \mathrm{Da}$ (ion at $\mathrm{m} / \mathrm{z} 221.1047$ ) also indicated that the propyl chain was not modified in M1. On the other hand, the ions at $\mathrm{m} / \mathrm{z} 123.0440$ and $\mathrm{m} / \mathrm{z} 137.0235$ would correspond to the ions at $\mathrm{m} / \mathrm{z} 135.0440$ and $\mathrm{m} / \mathrm{z} 149.0232$ of MDPV, indicating that the loss of the carbon atom was produced in the catechol moiety. M1 also showed ionization in negative mode (Table 2) suggesting the presence of an acidic centre like a phenol. Based on these data, 1-(3,4-dihydroxyphenyl)-2-(1pyrrolidinyl)pentan-1-one was proposed as the structure for M1.

\section{Metabolite M2}

M2 showed a $[\mathrm{M}+\mathrm{H}]^{+}$at $m / z 278.1747\left(\mathrm{C}_{16} \mathrm{H}_{24} \mathrm{NO}_{3}\right)$ which accounts for two hydrogen more than MDPV. Similarly to M1, M2 showed the ions at $m / z, 126.1277$ and $m / z 84.0809$ and the neutral losses of 71.0732 Da and 43.0544 Da (Table 3 and Figure S.3 in Electronic Supplementary Material), indicating that both the propyl and the pyrrolidine functions remained unaltered in M2. The ions at $\mathrm{m} / \mathrm{z} 137.0597$ and $\mathrm{m} / \mathrm{z}$ 151.0388 suggested a modification in the catechol moiety. The ionization in negative ionization mode of M2 (Table 2) was indicative of the presence of a phenolic function.

The methylation of M1 via Catechol-O-Methyl Transferase (COMT) seems to be the metabolic pathway involved in the formation of M2. Since COMT shows preference for 3-methylation against 4-methylation [18], 1-(4-hydroxy-3-methoxyphenyl)-2-(1-pyrrolidinyl)pentan-1-one was proposed as the structure for M2. 


\section{Metabolite M3}

Although nominally M3 and M2 are isobaric (molecular mass 277), accurate mass measurements revealed that their molecular formula significantly differed $\left(\mathrm{C}_{16} \mathrm{H}_{23} \mathrm{NO}_{3}\right.$ for $\mathrm{M} 2 \mathrm{vs}_{15} \mathrm{H}_{19} \mathrm{NO}_{4}$ for M3). Based on its formula, M3 involved demethylation and oxidation.

The product ion spectra (Table 3 and Figure S.4 in Electronic Supplementary Material) showed the ions at $\mathrm{m} / \mathrm{z}$ 193.0861, 175.0752, 137.0236 and 123.0440 which are common to those observed for M1. Similar to M1, the occurrence of these ions suggested that demethylation took place in the catechol moiety. This hypothesis was supported by the fact that $\mathrm{M} 3$ also exhibited a $[\mathrm{M}-\mathrm{H}]^{-}$in negative ionization mode (Table 2). On the other hand, the ions involving the pyrrolidin ring $(\mathrm{m} / \mathrm{z} 126.1277, \mathrm{~m} / \mathrm{z} 84.0810$ and neutral loss of 71.0721 Da in the parent drug) contained all now an extra oxygen atom and were moved $14 \mathrm{Da}$ in M3 ( $\mathrm{m} / \mathrm{z} 140.1069, \mathrm{~m} / \mathrm{z} 98.0601$ and neutral loss of $85.0528 \mathrm{Da})$ indicating an oxidation in this moiety. Therefore, 1-(3,4-dihydroxyphenyl)-2-(1-pyrrolidonyl)pentan-1-one was proposed as the structure for M3.

\section{Metabolite M4}

M4 showed ionization in both positive and negative modes (Table 2) both corresponding to a molecular formula of $\mathrm{C}_{16} \mathrm{H}_{21} \mathrm{NO}_{5}$ i.e. $\mathrm{M} 4$ differs two oxygen atoms from MDPV.

The product ion spectrum of M4 (Figure 3) showed a larger number of abundant ions than the one for MDPV (Figure 1). Among them, the ions at $\mathrm{m} / \mathrm{z} 149.0232$ and $\mathrm{m} / \mathrm{z} 135.0443$ indicated that the acetal moiety in the catechol remained unaltered in M4. Additionally, the ion at $m / z 205.0873$ suggested that all structural changes were focused on the pyrrolidin ring i.e. both oxygen atoms were added into this moiety. The ions at $\mathrm{m} / \mathrm{z}, 140.1071$ and $\mathrm{m} / \mathrm{z} 98.0602$ were common to the ones observed in M3 in which an oxydation in the pyrrolidine ring was postulated. Product ion spectrum for M4 also showed ions indicating an extra molecule of water in this ring $(\mathrm{m} / \mathrm{z} 158.1177$ and the neutral loss of 103.0621 Da in contrast with the neutral loss of 85.0528 Da showed in M3). All this information taken together allowed for proposing 1-(3,4-methylenedioxyphenyl)-2-(1-succinamic acid)pentan-1-one as the structure for M4. The oxydative opening of the pyrrolidin ring seems to be the most feasible metabolic pathway for the generation of M4. 
This opening is able to explain both the negative ionization observed despite the absence of any phenolic proton and the formation of all the product ions observed for M4 (Figure 3). The linear amine group together with the keto function at $\mathrm{C}_{1}$ facilitated the formation of the rearrangement previously reported for mephedrone [19].

\section{$\underline{\text { Metabolite M5 }}$}

The molecular formula of M5 $\left(\mathrm{C}_{16} \mathrm{H}_{23} \mathrm{NO}_{5}\right)$ implied the addition of two hydrogen and two oxygen atoms to MDPV. The product ion spectrum of M5 (Table 3 and Figure S.5 in Electronic Supplementary

Material) was almost identical to the one for M4 but with most of the ions with a difference of 2 Da. On one hand, the ions at $m / z 207.1035, m / z, 151.0388$ and $m / z 137.0597$ indicated the hydrolysis of the ketal moiety and the methylation of one of the hydroxyl groups of the catechol (as explained for M2). On the other hand, the ions at $\mathrm{m} / \mathrm{z} 140.1069$ and $\mathrm{m} / \mathrm{z} 98.0606$ are in agreement with an oxidation of the pyrrolidin ring (see M3) whereas the ion at $\mathrm{m} / z 158.1175$ and the neutral loss of 103.0621 Da suggested the opening of the ring (as explained for M4). Based on these results, 1-(4-hydroxy-3-methoxyphenyl)-2-(1succinamic acid)pentan-1-one was proposed as structure for M5.

\section{Metabolite M6 and M7}

Both M6 and M7 had a molecular formula of $\mathrm{C}_{16} \mathrm{H}_{21} \mathrm{NO}_{4}$. Both metabolites were ionized in both positive and negative ionization modes (Table 2) suggesting the presence of an acidic centre in both structures. Their product ion spectra (Table 3 and Figures S.6 and S.7 in Electronic Supplementary Material) were almost identical. The ions at $\mathrm{m} / \mathrm{z} 207.1026$ and $\mathrm{m} / \mathrm{z} 137.0598$ would indicate hydrolysis of the ketal function and methylation of the phenolic group of the catechol (as explained for M2 and M5). This metabolic pathway would also explain the negative ionization observed for M6 and M7. Additionally, the ions at $\mathrm{m} / \mathrm{z} 140.1073$ and $\mathrm{m} / \mathrm{z} 98.0603$ suggested an oxidation in the pyrrolidine ring whereas the ion at $m / z 175.0760$ implied that both the keto function at $C_{1}$ and the propyl chain remained unaltered.

The product ion spectra of both M6 and M7 were identical suggesting that they were isomers. Methylation of both hydroxyl groups of the catechol seems to be the most feasible metabolic pathway for the generation of these isomers. Since COMT shows preference for 3-methylation [11], this pathway was 
postulated to occur in the most abundant of both metabolites (M7) whereas 4-methylation was proposed for M6.

Therefore, 1-(3-hydroxy-4-methoxyphenyl)-2-(1-pyrrolidonyl)pentan-1-one and 1-(4-hydroxy-3methoxyphenyl)-2-(1-pyrrolidonyl)pentan-1-one were proposed as the structures for M6 and M7 respectively.

\section{$\underline{\text { Metabolite M8 }}$}

M8 was an isomeric metabolite of $\mathrm{M} 2$ (molecular formula $\mathrm{C}_{16} \mathrm{H}_{23} \mathrm{NO}_{3}$ ) i.e. it has two hydrogen atoms more than MDPV. However, the product ion spectrum of M8 (Table 3 and Figure S.8 in Electronic Supplementary Material) differed substantially from the one obtained for MDPV and M2. The spectrum was dominated by an abundant loss of water (ion at $\mathrm{m} / \mathrm{z}, 260.1641$ ). This abundant loss was not observed in other metabolites as it is characteristic of aliphatic hydroxyl groups. For this reason, reduction of the keto function at $\mathrm{C}_{1}$ seemed to be the most feasible metabolic pathway involved in the generation of M8. Additionally, the ions at $\mathrm{m} / \mathrm{z} 126.1278$ and $\mathrm{m} / \mathrm{z} 84.0809$ and the neutral loss of $71.073 \mathrm{Da}$ indicated an unaltered pyrrolidin ring whereas the neutral loss of 43. 0546 Da suggested that the propyl chain remained intact.

Based on these data, 1-(3,4-methylenedioxyphenyl)-2-(1-pyrrolidinyl)pentan-1-ol was proposed as structure for M8.

\section{$\underline{\text { Metabolite M9 }}$}

Based on its molecular formula $\left(\mathrm{C}_{16} \mathrm{H}_{25} \mathrm{NO}_{4}\right)$, M9 contains two hydrogen atoms and one oxygen more than MDPV. Similar to M2, the ions at $m / z, 151.0397$ and $m / z, 137.0603$ (Table 3 and Figure S.9 in Electronic Supplementary Material) indicated that M9 is a 3-methoxy-4-hydroxy-catechol-metabolite counting for the two extra hydrogen atoms. Therefore, hydroxylation of M2 seems to be the most feasible metabolic pathway involved in the formation of M9.

The product ion spectrum was examined in order to elucidate the location of the hydroxyl group. Ions at $\mathrm{m} / \mathrm{z} 151.0397$ and $\mathrm{m} / \mathrm{z} 137.0603$ indicated that hydroxylation did not take place in the catechol moiety. The ion at $m / z 72.0811$ and the neutral loss of $71.073 \mathrm{Da}$ (from $\mathrm{m} / \mathrm{z} 294$ to $\mathrm{m} / \mathrm{z} 223$ and from $\mathrm{m} / \mathrm{z} 276$ to 
$m / z$ 205) suggested that the pyrrolidine unit remained unaltered. However, nitrogen-containing ions at $m / z$ 98.0967 and $\mathrm{m} / \mathrm{z} 142.1230$ (not shown in other metabolites) indicated that hydroxylation took place close to the pyrrolidine ring.

The neutral loss of the propyl chain (43 Da) was not observed in M9. In contrast, subsequent neutral losses of water and propylene (18 Da and $42 \mathrm{Da}$ respectively) indicated that the propyl chain was hydroxylated. All this information taken together allowed for the proposal of 1-(4-hydroxy-3methoxyphenyl)-3-hydroxy-2-(1-pyrrolidinyl)pentan-1-one or 1-(4-hydroxy-3-methoxyphenyl)-4hydroxy-2-(1-pyrrolidinyl)pentan-1-one as a suitable structure for M9. With this information it is not possible to differentiate between both options.

\section{$\underline{\text { Metabolite M10 }}$}

M10 was an isomer of $\mathrm{M} 9\left(\mathrm{C}_{16} \mathrm{H}_{25} \mathrm{NO}_{4}\right)$ and also showed the ions at $\mathrm{m} / \mathrm{z} 137.0602$ and $\mathrm{m} / \mathrm{z}, 151.0395$ indicative of 3-methoxy-4-hydroxy-catechol metabolites. Therefore, in the same way as M9, hydroxylation of M2 was also considered as metabolic pathway for obtaining M10.

Product ion spectrum of M10 did exhibit neither the ions at $\mathrm{m} / \mathrm{z} 72$ and $\mathrm{m} / \mathrm{z} 84$ nor the neutral loss of 71 Da corresponding to the pyrrolidin function. In contrast, it showed a neutral loss of $87.0684 \mathrm{Da}$ (ion at $m / z 207.1023$ ) and the ions at $m / z 100.0759$ and 88.0761 (Table 3 and Figure S.10 in Electronic Supplementary Material). These results suggested that the hydroxyl group was placed on the pyrrolidine ring. Thus, 1-(4-hydroxy-3-methoxyphenyl)-2-(2-hydroxypyrrolidinyl)pentan-1-one or 1(4-hydroxy-3-methoxyphenyl)-2-(3-hydroxypyrrolidinyl)pentan-1-one could be proposed as the structure for M10. We have selected the first option as most plausible as it would be related with M6/M7, although the second candidate could not be discarded.

\subsection{MDPV phase II metabolites}

Once the 10 phase I metabolites were tentatively elucidated, nw-XICs at the calculated $\mathrm{m} / \mathrm{z}$ for the corresponding phase II metabolites (concretely glucuronides and sulphates) were reconstructed from the LE data in the non-hydrolyzed urine. In these cases, $\mathrm{MS}^{2}$ but also $\mathrm{MS}^{3}$ experiments were performed. In the latter case, the main product ion generated in the $\mathrm{MS}^{2}$ spectrum (corresponding to the loss of the sulphate or glucuronide group) was selected as precursor ion by increasing the cone voltage and acquiring 
the product ion scan of the generated in-source fragment. The structure of the non-conjugated part could be confirmed by comparing the corresponding $\mathrm{MS}^{3}$ fragmentation with the MS/MS spectra of the phase I metabolites. Using this approach, up to 7 glucuronides and 5 sulfates were detected (Table 2).

\subsection{Metabolic pathway for MDPV}

All this information taken together allowed for the proposal of a metabolic pathway for MDPV (Figure

4). The main reactions involved in MDPV metabolism are (i) hydrolysis of the ketal moiety of the catechol, (ii) methylation at C3', (iii) oxidation of the pyrrolidine ring, (iv) oxidative opening of the pyrrolidine ring, (v) reduction of the carbonyl group and (vi) hydroxylation.

In comparison to previously reported data, of the 10 tentatively identified metabolites, 5 have also been detected in rat urine samples (M1, M2, M3, M4, M7) [12,14,16], 6 in human urine (M1, M2, M3, M7, M8, M9) [12,15,16] and 3 after microbial biotransformation (M1, M2, M10) [1].

It is remarkable that, up to our knowledge, 2 of the metabolites identified in this paper have not been reported in the literature, concretely M5 and M6. In the case of M5, the same metabolic pathway has been proposed for similar compounds like $\alpha$-Pyrrolidinovalerophenone [20]. Regarding M6, this metabolite can be explained after the combination of two well-documented metabolic pathways for these compounds, i.e. oxidation of the pyrrolidin ring, hydrolysis of the ketal moiety of the catechol and methylation at C3'. Reference standards are not commercially available for these metabolites, and therefore their identity, although strongly supported by our QTOF MS accurate-mass data, could not be unequivocally confirmed. In summary, the proposed strategy allowed for the detection of MDPV and 10 potential metabolites. The use of a large volume injection ( $50 \mu \mathrm{L}$ in a $1.7 \mu \mathrm{m}$ LC column) improved the sensitivity of the method and the minimum sample preparation step minimised the possibility of losing part of the metabolites during the extraction process. However, both aspects of the experimental design might contribute to an inappropriate chromatographic behaviour. Therefore, the presence of additional isomers which might be not properly resolved under the experimental conditions cannot be discarded. 


\section{CONCLUSIONS}

The potential of UHPLC-QTOF $\mathrm{MS}^{\mathrm{E}}$ for the investigation of NPS metabolites in consumers' urine samples is illustrated, taking MDPV as a case of interest. In this paper, only a grab urine sample from a patient with MDPV-related disorder was available. Even in this case, where a control sample was not available, it was feasible to investigate the presence of known and unknown metabolites. Using a strategy based on the common fragmentation pathway of parent drug and metabolites, the detection of seven phase I metabolites was possible. The urinary excretion of some of them as glucuronides and sulfates was also identified. This strategy was extended to a second level, considering a common fragmentation pathway between a known metabolite, already detected in the sample, and other potential metabolites. This made the discovery of three additional metabolites possible. This strategy was based on the use of a QTOF instrument, which allows the full-spectrum acquisition in TOF MS mode with and without promoting fragmentation in the collision cell $\left(\mathrm{MS}^{\mathrm{E}}\right.$ acquisition). It was essential to first study the fragmentation pathway of the parent drug, which was facilitated by the accurate mass information provided by this analyzer. In addition, some MS/MS experiments were also performed, which gave relevant information about product ions and allowed elimination of interferences co-eluting with the analytes. The use of $\mathrm{MS}^{\mathrm{E}}$ together with additional analysis by MS/MS provided an excellent way of elucidating and/or confirming the presence of discovered metabolites. Data reported in this paper will be of help to develop future target quantitative methods for MDPV in urine focused on the most relevant metabolites present in the samples. Furthermore, these data may also be used with other purposes, e.g. to facilitate wastewater analysis in sewage-based epidemiology studies in order to estimate illicit drug consumption of a population.

\section{ACKNOWLEDGEMENTS}

The authors acknowledge the financial support of the Spanish Ministry of Economy and Competitiveness (CTQ2012-36189) and of Generalitat Valenciana (research group of excellence PROMETEOII/2014/023;

ISIC Envi-Food 2014/016). Spanish Health National System is acknowledged for O. J. Pozo contract (MS10/00576).

\section{CONFLICT OF INTEREST}

There are no financial or other relations that could lead to a conflict of interest. 


\section{FIGURE LEGENDS}

Fig. 1. Product ion spectrum of MDPV $(20 \mathrm{eV})$ and proposed fragmentation pathway.

Fig. 2. (a1)Total Ion Current (TIC) chromatogram of the low energy function (LE) of the hydrolysed urine (a2) TIC of the high energy function (HE) of the hydrolysed urine (only showed from 1 to $7 \mathrm{~min}$ ); (b) nw-XIC at $\mathrm{m} / z, 175.075$ in HE function; (c) HE spectra for peaks at 2.75 and $4.55 \mathrm{~min}$; (d) LE spectra for peaks at 2.75 and $4.55 \mathrm{~min}$; (e) nw-XIC for peaks detected at 2.75 and $4.55 \mathrm{~min}$ in LE function

Fig. 3. Product ion spectrum of M4 (20 eV) and proposed fragmentation pathway.

Fig.4.Metabolic pathway proposed for MDPV. U: metabolites excreted unconjugated, G: metabolites excreted as glucuronides, S: metabolites excreted as sulfates. ${ }^{*}$ M6 (not shown in the Figure) is the $\mathrm{C}_{4}$, methylated isomer of $\mathrm{M} 7$ which is methylated in $\mathrm{C}_{3}$, (shown in the Figure) 


\section{REFERENCES}

[1] Mardal M, Meyer MR (2014) Studies on the microbial biotransformation of the novel psychoactive substance methylenedioxypyrovalerone (MDPV) in wastewater by means of liquid chromatography-high resolution mass spectrometry/mass spectrometry. Sci. Total. Environ. 493: 588-595.

[2] van Nuijs AL, Gheorghe A, Jorens PG, Maudens K, Neels H, Covaci A (2013) Optimization, validation, and the application of liquid chromatography-tandem mass spectrometry for the analysis of new drugs of abuse in wastewater. Drug Test. Anal. 6: 861-867

[3] Ort C, van Nuijs A, Berset JD, Bijlsma L, Castiglioni S, Covaci A, de Voogt P, Emke E, FattaKassinos D, Griffiths P., Hernández F, González-Marino I, Grabic R, Kasprzyk-Hordern B, Mastroianni N., Meierjohann A, Néfau T, Östman M, Picó Y, Racamonde I, Reid M, Slobodnik J, Terzic S, Thomaidis N, Thomas K (2014) Spatial differences and temporal changes in illicit drug use in Europe quantified by wastewater analysis. Addiction 109: 1338-1352

[4] G. Gardos, J.O. Cole. Evaluation of pyrovalerone in chronically fatigued volunteers. Curr. Ther. Res. 13 (1971) 631-635

[5] P. Deniker, H. Loo, H. Cuche, J.M. Roux (1975) Abuse of pyrovalerone by drug addicts. Ann. Med. Psychol. 2: 745-748

[6] http://www.elmundo.es/baleares/2014/06/30/53b0f939ca47414e5d8b456d.html (last accessed $15 / 10 / 2014)$

[7] http://www.abc.es/local-baleares/20140705/abci-britanica-muerde-magaluf-201407051225.html (last accessed 15/10/2014)].

[8] Hernández F, Grimalt S, Pozo ÓJ, Sancho JV (2009) Use of ultra-high-pressure liquid chromatography-quadrupole time-of-flight MS to discover the presence of pesticide metabolites in food samples. J. Sep. Sci. 32: 2245-2261

[9] Thurman EM, Ferrer I, Zavitsanos P, Zweigenbaum JA (2013) Identification of imidacloprid metabolites in onion (Allium cepa L.) using high-resolution mass spectrometry and accurate mass tools. Rapid Commun. Mass Spectrom. 27: 1891-1903

[10] Díaz R, Ibáñez M, Sancho JV, Hernández F (2012) Target and non-target screening strategies for organic contaminants, residues and illicit substances in food, environmental and human biological samples by UHPLC-QTOF-MS. Anal. Meth. 4: 196-217 
[11] Hernández F, Bijlsma L, Sancho JV, Díaz R, Ibáñez M (2011) Rapid wide-scope screening of drugs of abuse, prescription drugs with potential for abuse and their metabolites in influent and effluent urban wastewater by ultrahigh pressure liquid chromatography-quadrupole-time-of-flight-mass spectrometry. Anal Chim Acta. 684: 96-106

[12] Meyer MR, Du P, Schuster F, Maurer H (2010). Studies on the metabolism of the $\alpha$ pyrrolidinophenone designer drug methylenedioxy-pyrovalerone (MDPV) in rat and human urine and human liver microsomes using GC-MS and LC-high-resolution MS and its detectability in urine by GCMS. J. Mass Spectrom. 45: 1426-1442

[13] Strano-Rossi S, Cadwallader AB, de la Torre X, Botrè F (2010) Toxicological determination and in vitro metabolism of the new designer drug methylenedioxypyrovalerone (MDPV) by gas chromatography/mass spectrometry and liquid chromatography/quadrupole time-of-flight mass spectrometry. Rapid Commun. Mass Spectrom. 24: 2706-2714

[14] Anizan S, Ellefsen K, Concheiro M, Suzuki M, Rice KC, Baumann MH, Huestis MA (2014) 3,4Methylenedioxypyrovalerone (MDPV) and metabolites quantification in human and rat plasma by liquid chromatography-high resolution mass spectrometry Anal Chim Acta. 827: 54-63.

[15] Bertol E, Mari F, Boscolo-Berto R, Mannaioni G, Vaiano F, Favretto D (2014) A mixed MDPV and benzodiazepine intoxication in a chronic drug abuser: Determination of MDPV metabolites by LCHRMS and discussion of the case. A mixed MDPV and benzodiazepine intoxication in a chronic drug abuser: Determination of MDPV metabolites by LC-HRMS and discussion of the case, Forensic Sci. Int. 24: $149-155$

[16] M. Paul, J. Ippisch, C. Herrmann, S. Guber, W. Schultis. Analysis of new designer drugs and common drugs of abuse in urine by a combined targeted and untargeted LC-HR-QTOFMS approach. Anal. Bioanal. Chem. 406 (2014) 4425-4441

[17] Hernández F, Sancho JV, Pozo OJ (2004) An estimation of the exposure to organophosphorus pesticides through the simultaneous determination of their main metabolites in urine by liquid chromatography-tandem mass spectrometry. J. Chromatogr. B Anal. Technol. Biomed. Life Sci. 808: 229-239

[18] Zhu BT (2002) Catechol-O-methyltransferase(COMT)-mediated methylation metabolism of endogenous bioactive catechols and modulation by endobiotics and xenobiotics: Importance in pathophysiology and pathogenesis. Curr. Drug Metabol. 2002: 321 
[19] Pozo OJ, Ibáñez M, Sancho JV, Lahoz-Beneytez J, Farré M, Papaseit E, de la Torre R, Hernández F (2015) Evaluation of mephedrone in vivo human metabolismby ultra high performance líquid chromatography coupled to hybrid quadrupole-time of Flight mass spectrometry. Drug Metabol. Disp. 43: $248-257$

[20] Sauer C, Peters FT, Haas C, Meyer MR, Fritschi G, Maurer HH (2009) New Designer Drug $\alpha$ Pyrrolidinovalerophenone (PVP): Studies on its Metabolism and Toxicological Detection in Rat Urine Using Gas Chromatographic / Mass Spectrometric Techniques. J. Mass Spectrom. 44: 952-964. 


\section{TABLES}

Table 1. Detection of MDPV metabolites by common fragments, extracted in the high collision energy function of the $\mathrm{MS}^{\mathrm{E}}$ acquisition mode.

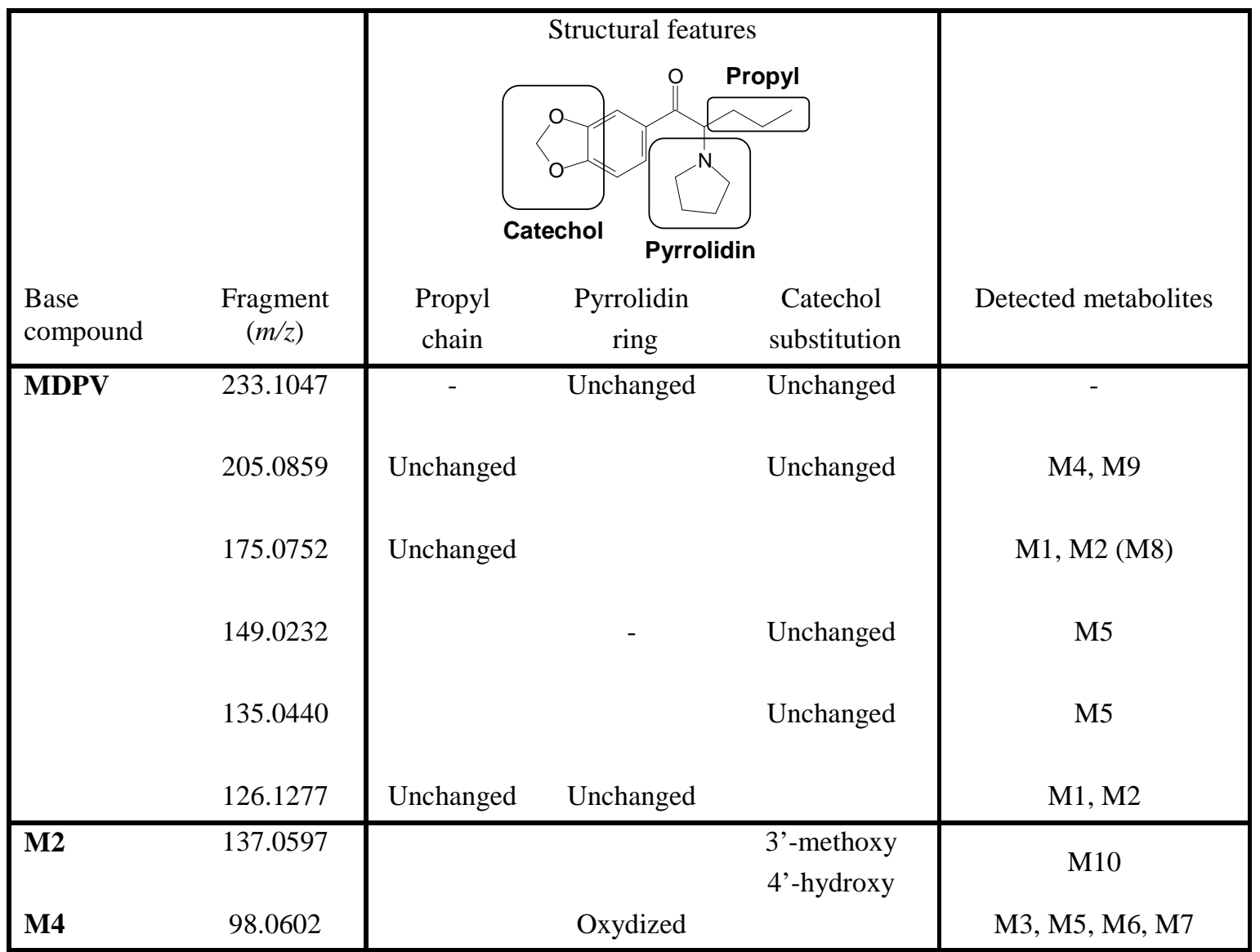

*Although all fragment ions for all metabolites were used for the iterative process, only those which contribute to find additional metabolites have been included in this table. 
1 Table 2. Retention time, ionization behaviour and phase I/phase II species found for the detected metabolites.

\begin{tabular}{|c|c|c|c|c|c|c|c|c|c|}
\hline \multirow[b]{2}{*}{ Compound } & \multirow[b]{2}{*}{$\begin{array}{c}\mathbf{R t} \\
(\mathbf{m i n})\end{array}$} & \multicolumn{5}{|c|}{ Ionization } & \multicolumn{3}{|c|}{ phase I/phase II metabolism } \\
\hline & & $\begin{array}{l}\text { Ionization } \\
\text { Mode }\end{array}$ & Species & $\begin{array}{c}\text { Elemental } \\
\text { composition }\end{array}$ & $m / z$ & $\begin{array}{l}\text { Error } \\
(\mathbf{m D a})\end{array}$ & Unconjugated & Glucuronide & Sulphate \\
\hline MDPV & 5.47 & ESI+ & {$[\mathrm{M}+\mathrm{H}]^{+}$} & $\mathrm{C}_{16} \mathrm{H}_{22} \mathrm{NO}_{3}$ & 276.1590 & -1.0 & $\checkmark$ & n.d. & n.d. \\
\hline \multirow[t]{2}{*}{ M1 } & \multirow[t]{2}{*}{2.75} & ESI+ & {$[\mathrm{M}+\mathrm{H}]^{+}$} & $\mathrm{C}_{15} \mathrm{H}_{22} \mathrm{NO}_{3}$ & 264.1593 & -0.7 & \multirow[t]{2}{*}{ n.d. } & \multirow[t]{2}{*}{$\checkmark$} & \multirow[t]{2}{*}{$\checkmark$} \\
\hline & & ESI- & {$[\mathrm{M}-\mathrm{H}]^{-}$} & $\mathrm{C}_{15} \mathrm{H}_{20} \mathrm{NO}_{3}$ & 262.1445 & 0.2 & & & \\
\hline \multirow[t]{2}{*}{ M2 } & \multirow[t]{2}{*}{4.57} & ESI+ & {$[\mathrm{M}+\mathrm{H}]^{+}$} & $\mathrm{C}_{16} \mathrm{H}_{24} \mathrm{NO}_{3}$ & 278.1747 & -0.9 & \multirow[t]{2}{*}{$\checkmark$} & \multirow[t]{2}{*}{$\checkmark$} & \multirow[t]{2}{*}{$\checkmark$} \\
\hline & & ESI- & {$[\mathrm{M}-\mathrm{H}]^{-}$} & $\mathrm{C}_{16} \mathrm{H}_{22} \mathrm{NO}_{3}$ & 276.1589 & -1.5 & & & \\
\hline \multirow[t]{2}{*}{ M3 } & \multirow[t]{2}{*}{7.85} & ESI+ & {$[\mathrm{M}+\mathrm{H}]^{+}$} & $\mathrm{C}_{15} \mathrm{H}_{20} \mathrm{NO}_{4}$ & 278.1389 & -0.3 & \multirow[t]{2}{*}{ n.d. } & \multirow[t]{2}{*}{ n.d. } & \multirow[t]{2}{*}{$\checkmark$} \\
\hline & & ESI- & {$[\mathrm{M}-\mathrm{H}]^{-}$} & $\mathrm{C}_{15} \mathrm{H}_{18} \mathrm{NO}_{4}$ & 276.1227 & -0.2 & & & \\
\hline \multirow[t]{2}{*}{ M4 } & \multirow[t]{2}{*}{5.7} & ESI+ & {$[\mathrm{M}+\mathrm{H}]^{+}$} & $\mathrm{C}_{16} \mathrm{H}_{22} \mathrm{NO}_{5}$ & 308.1494 & -0.4 & \multirow[t]{2}{*}{$\checkmark$} & \multirow[t]{2}{*}{ n.d. } & \multirow[t]{2}{*}{ n.d. } \\
\hline & & ESI- & {$[\mathrm{M}+\mathrm{H}]^{-}$} & $\mathrm{C}_{16} \mathrm{H}_{20} \mathrm{NO}_{5}$ & 306.1331 & -1.0 & & & \\
\hline \multirow[t]{2}{*}{ M5 } & \multirow[t]{2}{*}{4.5} & ESI+ & {$[\mathrm{M}+\mathrm{H}]^{+}$} & $\mathrm{C}_{16} \mathrm{H}_{24} \mathrm{NO}_{5}$ & 310.1646 & -0.8 & \multirow[t]{2}{*}{$\checkmark$} & \multirow[t]{2}{*}{ n.d. } & \multirow[t]{2}{*}{$\checkmark$} \\
\hline & & ESI- & {$[\mathrm{M}-\mathrm{H}]^{-}$} & $\mathrm{C}_{16} \mathrm{H}_{22} \mathrm{NO}_{5}$ & 308.1488 & -1.0 & & & \\
\hline \multirow[t]{2}{*}{ M6 } & \multirow[t]{2}{*}{8.52} & ESI+ & {$[\mathrm{M}+\mathrm{H}]^{+}$} & $\mathrm{C}_{16} \mathrm{H}_{22} \mathrm{NO}_{4}$ & 292.1554 & 0.5 & \multirow[t]{2}{*}{ n.d. } & \multirow[t]{2}{*}{$\checkmark$} & \multirow[t]{2}{*}{ n.d. } \\
\hline & & ESI- & {$[\mathrm{M}-\mathrm{H}]^{-}$} & $\mathrm{C}_{16} \mathrm{H}_{20} \mathrm{NO}_{4}$ & 290.1392 & 0 & & & \\
\hline M7 & 8.78 & ESI+ & {$[\mathrm{M}+\mathrm{H}]^{+}$} & $\mathrm{C}_{16} \mathrm{H}_{22} \mathrm{NO}_{4}$ & 292.1551 & 0.2 & n.d. & $\checkmark$. & n.d. \\
\hline & & ESI- & {$[\mathrm{M}-\mathrm{H}]^{-}$} & $\mathrm{C}_{16} \mathrm{H}_{20} \mathrm{NO}_{4}$ & 290.1390 & -0.2 & & & \\
\hline M8 & 5.3 & ESI+ & {$[\mathrm{M}+\mathrm{H}]^{+}$} & $\mathrm{C}_{16} \mathrm{H}_{24} \mathrm{NO}_{3}$ & 278.1747 & -0.9 & $\checkmark$ & n.d. & n.d. \\
\hline M9 & 2.8 & ESI+ & {$[\mathrm{M}+\mathrm{H}]^{+}$} & $\mathrm{C}_{16} \mathrm{H}_{24} \mathrm{NO}_{4}$ & 294.1709 & 0.4 & n.d. & n.d. & $\checkmark$ \\
\hline M10 & 4.4 & ESI+ & {$[\mathrm{M}+\mathrm{H}]^{+}$} & $\mathrm{C}_{16} \mathrm{H}_{24} \mathrm{NO}_{4}$ & 294.1707 & 0.2 & n.d. & $\checkmark$ & n.d. \\
\hline
\end{tabular}


4 Table 3. Product ions found in positive ionization mode for the detected metabolites.

\begin{tabular}{|c|c|c|c|c|c|c|c|c|}
\hline Metabolite & $m / z$ & $\begin{array}{l}\text { Error } \\
(\mathbf{m D a})\end{array}$ & $\begin{array}{c}\text { Elemental } \\
\text { composition }\end{array}$ & Precursor ion & Product ion & $\begin{array}{c}\text { Abundance } \\
(\%)\end{array}$ & $\begin{array}{l}\text { Error } \\
\text { (mDa) }\end{array}$ & Formula \\
\hline MDPV & 276.1590 & -1.0 & $\mathrm{C}_{16} \mathrm{H}_{22} \mathrm{NO}_{3}$ & 276 & $\begin{array}{c}233.1047 \\
205.0859 \\
175.0753 \\
149.0233 \\
135.0440 \\
126.1277 \\
121.0293 \\
84.0810\end{array}$ & $\begin{array}{c}8 \\
86 \\
92 \\
40 \\
70 \\
90 \\
2 \\
4\end{array}$ & $\begin{array}{c}-0.5 \\
-0.6 \\
-0.6 \\
-0.7 \\
-0.6 \\
-0.6 \\
0.3 \\
-0.3\end{array}$ & $\begin{array}{c}\mathrm{C}_{13} \mathrm{H}_{15} \mathrm{NO}_{3} \\
\mathrm{C}_{12} \mathrm{H}_{13} \mathrm{O}_{3} \\
\mathrm{C}_{11} \mathrm{H}_{11} \mathrm{O}_{2} \\
\mathrm{C}_{8} \mathrm{H}_{5} \mathrm{O}_{3} \\
\mathrm{C}_{8} \mathrm{H}_{7} \mathrm{O}_{2} \\
\mathrm{C}_{8} \mathrm{H}_{16} \mathrm{~N} \\
\mathrm{C}_{7} \mathrm{H}_{5} \mathrm{O}_{2} \\
\mathrm{C}_{5} \mathrm{H}_{10} \mathrm{~N}\end{array}$ \\
\hline M1 & 264.1593 & -0.7 & $\mathrm{C}_{15} \mathrm{H}_{22} \mathrm{NO}_{3}$ & 264 & $\begin{array}{c}221.1047 \\
193.0861 \\
175.0754 \\
165.0912 \\
137.0235 \\
126.1278 \\
123.0440 \\
84.0809 \\
72.0809 \\
\end{array}$ & $\begin{array}{c}8 \\
47 \\
35 \\
5 \\
32 \\
72 \\
70 \\
5 \\
44 \\
\end{array}$ & $\begin{array}{l}-0.5 \\
-0.4 \\
-0.5 \\
-0.4 \\
-0.4 \\
-0.5 \\
-0.6 \\
-0.4 \\
-0.4 \\
\end{array}$ & $\begin{array}{c}\mathrm{C}_{12} \mathrm{H}_{15} \mathrm{NO}_{3} \\
\mathrm{C}_{11} \mathrm{H}_{13} \mathrm{O}_{3} \\
\mathrm{C}_{11} \mathrm{H}_{11} \mathrm{O}_{2} \\
\mathrm{C}_{10} \mathrm{H}_{13} \mathrm{O}_{2} \\
\mathrm{C}_{7} \mathrm{H}_{5} \mathrm{O}_{3} \\
\mathrm{C}_{8} \mathrm{H}_{16} \mathrm{~N} \\
\mathrm{C}_{7} \mathrm{H}_{7} \mathrm{O}_{2} \\
\mathrm{C}_{5} \mathrm{H}_{10} \mathrm{~N} \\
\mathrm{C}_{4} \mathrm{H}_{10} \mathrm{~N} \\
\end{array}$ \\
\hline M2 & 278.1747 & -0.9 & $\mathrm{C}_{16} \mathrm{H}_{24} \mathrm{NO}_{3}$ & 278 & $\begin{array}{c}235.1203 \\
207.1015 \\
175.0751 \\
151.0388 \\
137.0597 \\
126.1277 \\
84.0809 \\
72.0808\end{array}$ & $\begin{array}{c}4 \\
39 \\
100 \\
30 \\
33 \\
75 \\
4 \\
12\end{array}$ & $\begin{array}{l}-0.5 \\
-0.6 \\
-0.8 \\
-0.7 \\
-0.6 \\
-0.6 \\
-0.4 \\
-0.5\end{array}$ & $\begin{array}{c}\mathrm{C}_{13} \mathrm{H}_{17} \mathrm{NO}_{3} \\
\mathrm{C}_{12} \mathrm{H}_{15} \mathrm{O}_{3} \\
\mathrm{C}_{11} \mathrm{H}_{11} \mathrm{O}_{2} \\
\mathrm{C}_{8} \mathrm{H}_{7} \mathrm{O}_{3} \\
\mathrm{C}_{8} \mathrm{H}_{9} \mathrm{O}_{2} \\
\mathrm{C}_{8} \mathrm{H}_{16} \mathrm{~N} \\
\mathrm{C}_{5} \mathrm{H}_{10} \mathrm{~N} \\
\mathrm{C}_{4} \mathrm{H}_{10} \mathrm{~N}\end{array}$ \\
\hline M3 & 278.1389 & -0.3 & $\mathrm{C}_{15} \mathrm{H}_{20} \mathrm{NO}_{4}$ & 278 & $\begin{array}{c}260.1282 \\
193.0861 \\
175.0752 \\
140.1069 \\
137.0236 \\
123.0440 \\
98.0601 \\
86.0602\end{array}$ & $\begin{array}{c}8 \\
8 \\
10 \\
100 \\
2 \\
11 \\
25 \\
11\end{array}$ & $\begin{array}{l}-0.5 \\
-0.4 \\
-0.7 \\
-0.6 \\
-0.3 \\
-0.6 \\
-0.5 \\
-0.4\end{array}$ & $\begin{array}{c}\mathrm{C}_{15} \mathrm{H}_{18} \mathrm{NO}_{3} \\
\mathrm{C}_{11} \mathrm{H}_{13} \mathrm{O}_{3} \\
\mathrm{C}_{11} \mathrm{H}_{11} \mathrm{O}_{2} \\
\mathrm{C}_{8} \mathrm{H}_{14} \mathrm{NO} \\
\mathrm{C}_{7} \mathrm{H}_{5} \mathrm{O}_{3} \\
\mathrm{C}_{7} \mathrm{H}_{7} \mathrm{O}_{2} \\
\mathrm{C}_{5} \mathrm{H}_{8} \mathrm{NO} \\
\mathrm{C}_{4} \mathrm{H}_{8} \mathrm{NO}\end{array}$ \\
\hline
\end{tabular}




\begin{tabular}{|c|c|c|c|c|c|c|c|c|}
\hline Metabolite & $m / z$ & $\begin{array}{l}\text { Error } \\
(\mathrm{mDa})\end{array}$ & $\begin{array}{c}\text { Elemental } \\
\text { composition }\end{array}$ & Precursor ion & Product ion & $\begin{array}{c}\text { Abundance } \\
(\%)\end{array}$ & $\begin{array}{l}\text { Error } \\
(\mathrm{mDa})\end{array}$ & Formula \\
\hline \multirow[t]{17}{*}{ M4 } & 308.1494 & -0.4 & $\mathrm{C}_{16} \mathrm{H}_{22} \mathrm{NO}_{5}$ & 308 & 290.1387 & 100 & -0.5 & $\mathrm{C}_{16} \mathrm{H}_{20} \mathrm{NO}_{4}$ \\
\hline & & & & & 272.1283 & 40 & -0.4 & $\mathrm{C}_{16} \mathrm{H}_{18} \mathrm{NO}_{3}$ \\
\hline & & & & & 260.1283 & 50 & -0.4 & $\mathrm{C}_{15} \mathrm{H}_{18} \mathrm{NO}_{3}$ \\
\hline & & & & & 242.1179 & 20 & -0.2 & $\mathrm{C}_{15} \mathrm{H}_{16} \mathrm{NO}_{2}$ \\
\hline & & & & & 230.0814 & 27 & -0.3 & $\mathrm{C}_{13} \mathrm{H}_{12} \mathrm{NO}_{3}$ \\
\hline & & & & & 214.1230 & 27 & -0.2 & $\mathrm{C}_{14} \mathrm{H}_{16} \mathrm{NO}$ \\
\hline & & & & & 205.0873 & 53 & 0.8 & $\mathrm{C}_{12} \mathrm{H}_{13} \mathrm{O}_{3}$ \\
\hline & & & & & 204.1017 & 54 & -0.8 & $\mathrm{C}_{12} \mathrm{H}_{14} \mathrm{NO}_{2}$ \\
\hline & & & & & 203.0943 & 21 & -0.3 & $\mathrm{C}_{12} \mathrm{H}_{13} \mathrm{NO}_{2}$ \\
\hline & & & & & 175.0756 & 48 & -0.3 & $\mathrm{C}_{11} \mathrm{H}_{11} \mathrm{O}_{2}$ \\
\hline & & & & & 174.0916 & 40 & -0.3 & $\mathrm{C}_{11} \mathrm{H}_{12} \mathrm{NO}$ \\
\hline & & & & & 158.1177 & 18 & -0.4 & $\mathrm{C}_{8} \mathrm{H}_{16} \mathrm{NO}_{2}$ \\
\hline & & & & & 149.0232 & 12 & -0.7 & $\mathrm{C}_{8} \mathrm{H}_{5} \mathrm{O}_{3}$ \\
\hline & & & & & 140.1071 & 100 & -0.4 & $\mathrm{C}_{8} \mathrm{H}_{14} \mathrm{NO}$ \\
\hline & & & & & 135.0443 & 30 & -0.3 & $\mathrm{C}_{8} \mathrm{H}_{7} \mathrm{O}_{2}$ \\
\hline & & & & & 98.0602 & 14 & -0.4 & $\mathrm{C}_{5} \mathrm{H}_{8} \mathrm{NO}$ \\
\hline & & & & & 87.0443 & 27 & -0.3 & $\mathrm{C}_{4} \mathrm{H}_{7} \mathrm{O}_{2}$ \\
\hline \multirow[t]{17}{*}{ M5 } & 310.1646 & -0.8 & $\mathrm{C}_{16} \mathrm{H}_{24} \mathrm{NO}_{5}$ & 310 & 292.1540 & 90 & -0.9 & $\mathrm{C}_{16} \mathrm{H}_{22} \mathrm{NO}_{4}$ \\
\hline & & & & & 274.1435 & 40 & -0.8 & $\mathrm{C}_{16} \mathrm{H}_{20} \mathrm{NO}_{3}$ \\
\hline & & & & & 260.1279 & 60 & -0.8 & $\mathrm{C}_{15} \mathrm{H}_{18} \mathrm{NO}_{3}$ \\
\hline & & & & & 242.1184 & 22 & 0.3 & $\mathrm{C}_{15} \mathrm{H}_{16} \mathrm{NO}_{2}$ \\
\hline & & & & & 232.0977 & 20 & 0.3 & $\mathrm{C}_{13} \mathrm{H}_{14} \mathrm{NO}_{3}$ \\
\hline & & & & & 207.1035 & 28 & -1.3 & $\mathrm{C}_{12} \mathrm{H}_{15} \mathrm{O}_{3}$ \\
\hline & & & & & 206.1171 & 48 & -1.0 & $\mathrm{C}_{12} \mathrm{H}_{16} \mathrm{NO}_{2}$ \\
\hline & & & & & 205.1098 & 20 & -0.5 & $\mathrm{C}_{12} \mathrm{H}_{15} \mathrm{NO}_{2}$ \\
\hline & & & & & 175.0757 & 62 & -0.2 & $\mathrm{C}_{11} \mathrm{H}_{11} \mathrm{O}_{2}$ \\
\hline & & & & & 174.0912 & 55 & -0.7 & $\mathrm{C}_{11} \mathrm{H}_{12} \mathrm{NO}$ \\
\hline & & & & & 158.1175 & 30 & -0.6 & $\mathrm{C}_{8} \mathrm{H}_{16} \mathrm{NO}_{2}$ \\
\hline & & & & & 151.0388 & 13 & -0.7 & $\mathrm{C}_{8} \mathrm{H}_{7} \mathrm{O}_{3}$ \\
\hline & & & & & 140.1069 & 100 & -0.6 & $\mathrm{C}_{8} \mathrm{H}_{14} \mathrm{NO}$ \\
\hline & & & & & 137.0597 & 14 & -0.6 & $\mathrm{C}_{8} \mathrm{H}_{9} \mathrm{O}_{2}$ \\
\hline & & & & & 104.0711 & 10 & -0.1 & $\mathrm{C}_{4} \mathrm{H}_{10} \mathrm{NO}_{2}$ \\
\hline & & & & & 98.0606 & 13 & 0 & $\mathrm{C}_{5} \mathrm{H}_{8} \mathrm{NO}$ \\
\hline & & & & & 87.0442 & 25 & -0.4 & $\mathrm{C}_{4} \mathrm{H}_{7} \mathrm{O}_{2}$ \\
\hline
\end{tabular}




\begin{tabular}{|c|c|c|c|c|c|c|c|c|}
\hline Metabolite & $m / z$ & $\begin{array}{l}\text { Error } \\
(\mathrm{mDa})\end{array}$ & $\begin{array}{c}\text { Elemental } \\
\text { composition }\end{array}$ & Precursor ion & Product ion & $\begin{array}{c}\text { Abundance } \\
(\%)\end{array}$ & $\begin{array}{l}\text { Error } \\
(\mathrm{mDa})\end{array}$ & Formula \\
\hline \multirow[t]{7}{*}{ M6 } & 292.1554 & 0.5 & $\mathrm{C}_{16} \mathrm{H}_{22} \mathrm{NO}_{4}$ & 292 & 274.1440 & 5 & -0.3 & $\mathrm{C}_{16} \mathrm{H}_{20} \mathrm{NO}_{3}$ \\
\hline & & & & & 207.1026 & 8 & 0.5 & $\mathrm{C}_{12} \mathrm{H}_{15} \mathrm{O}_{3}$ \\
\hline & & & & & 175.0760 & 10 & 0.1 & $\mathrm{C}_{11} \mathrm{H}_{11} \mathrm{O}_{2}$ \\
\hline & & & & & 140.1073 & 100 & -0.2 & $\mathrm{C}_{8} \mathrm{H}_{14} \mathrm{NO}$ \\
\hline & & & & & 137.0598 & 10 & -0.5 & $\mathrm{C}_{8} \mathrm{H}_{9} \mathrm{O} 2$ \\
\hline & & & & & 98.0603 & 20 & -0.3 & $\mathrm{C}_{5} \mathrm{H}_{8} \mathrm{NO}$ \\
\hline & & & & & 86.0600 & 3 & -0.6 & $\mathrm{C}_{4} \mathrm{H}_{8} \mathrm{NO}$ \\
\hline \multirow[t]{7}{*}{ M7 } & 292.1546 & 0.2 & $\mathrm{C}_{16} \mathrm{H}_{22} \mathrm{NO}_{4}$ & 292 & 274.1439 & 5 & -0.4 & $\mathrm{C}_{16} \mathrm{H}_{20} \mathrm{NO}_{3}$ \\
\hline & & & & & 207.1021 & 5 & 0 & $\mathrm{C}_{12} \mathrm{H}_{15} \mathrm{O}_{3}$ \\
\hline & & & & & 175.0759 & 8 & 0 & $\mathrm{C}_{11} \mathrm{H}_{11} \mathrm{O}_{2}$ \\
\hline & & & & & 140.1072 & 100 & -0.3 & $\mathrm{C}_{8} \mathrm{H}_{14} \mathrm{NO}$ \\
\hline & & & & & 137.0601 & 6 & -0.2 & $\mathrm{C}_{8} \mathrm{H}_{9} \mathrm{O}_{2}$ \\
\hline & & & & & 98.0604 & 20 & -0.2 & $\mathrm{C}_{5} \mathrm{H}_{8} \mathrm{NO}$ \\
\hline & & & & & 86.0603 & 3 & -0.3 & $\mathrm{C}_{4} \mathrm{H}_{8} \mathrm{NO}$ \\
\hline \multirow[t]{8}{*}{ M8 } & 278.1747 & -0.9 & $\mathrm{C}_{16} \mathrm{H}_{24} \mathrm{NO}_{3}$ & 278 & 260.1641 & 100 & -1.0 & $\mathrm{C}_{16} \mathrm{H}_{22} \mathrm{NO}_{2}$ \\
\hline & & & & & 217.1095 & 58 & -0.8 & $\mathrm{C}_{13} \mathrm{H}_{15} \mathrm{NO}_{2}$ \\
\hline & & & & & 207.1017 & 3 & -0.4 & $\mathrm{C}_{12} \mathrm{H}_{15} \mathrm{O}_{3}$ \\
\hline & & & & & 175.0754 & 8 & -0.5 & $\mathrm{C}_{11} \mathrm{H}_{11} \mathrm{O}_{2}$ \\
\hline & & & & & 159.0804 & 6 & -0.6 & $\mathrm{C}_{11} \mathrm{H}_{11} \mathrm{O}$ \\
\hline & & & & & 126.1278 & 6 & -0.5 & $\mathrm{C}_{8} \mathrm{H}_{16} \mathrm{~N}$ \\
\hline & & & & & 84.0809 & 2 & -0.4 & $\mathrm{C}_{5} \mathrm{H}_{10} \mathrm{~N}$ \\
\hline & & & & & 72.0808 & 3 & -0.5 & $\mathrm{C}_{4} \mathrm{H}_{10} \mathrm{~N}$ \\
\hline \multirow[t]{12}{*}{ M9 } & 294.1709 & 0.4 & $\mathrm{C}_{16} \mathrm{H}_{24} \mathrm{NO}_{4}$ & 294 & 276.1595 & 8 & -0.5 & $\mathrm{C}_{16} \mathrm{H}_{22} \mathrm{NO}_{3}$ \\
\hline & & & & & 234.1135 & 58 & 0.5 & $\mathrm{C}_{13} \mathrm{H}_{16} \mathrm{NO}_{3}$ \\
\hline & & & & & 223.0973 & 4 & 0.3 & $\mathrm{C}_{12} \mathrm{H}_{15} \mathrm{O}_{4}$ \\
\hline & & & & & 216.1026 & 4 & 0.2 & $\mathrm{C}_{13} \mathrm{H}_{14} \mathrm{NO}_{2}$ \\
\hline & & & & & 205.0867 & 10 & 0.2 & $\mathrm{C}_{12} \mathrm{H}_{13} \mathrm{O}_{3}$ \\
\hline & & & & & 200.1074 & 19 & -0.1 & $\mathrm{C}_{13} \mathrm{H}_{14} \mathrm{NO}$ \\
\hline & & & & & 173.0614 & 2 & 1.1 & $\mathrm{C}_{11} \mathrm{H}_{9} \mathrm{O}_{2}$ \\
\hline & & & & & 177.0545 & 5 & -0.7 & $\mathrm{C}_{10} \mathrm{H}_{9} \mathrm{O}_{3}$ \\
\hline & & & & & 151.0397 & 9 & 0.2 & $\mathrm{C}_{8} \mathrm{H}_{7} \mathrm{O}_{3}$ \\
\hline & & & & & 142.1230 & 27 & -0.2 & $\mathrm{C}_{8} \mathrm{H}_{16} \mathrm{NO}$ \\
\hline & & & & & 137.0603 & 20 & 0 & $\mathrm{C}_{8} \mathrm{H}_{9} \mathrm{O}_{2}$ \\
\hline & & & & & 98.0967 & 9 & -0.3 & $\mathrm{C}_{6} \mathrm{H}_{12} \mathrm{~N}$ \\
\hline
\end{tabular}




\begin{tabular}{|c|c|c|c|c|c|c|c|c|}
\hline Metabolite & $m / z$ & $\begin{array}{l}\text { Error } \\
(\mathrm{mDa})\end{array}$ & $\begin{array}{c}\text { Elemental } \\
\text { composition }\end{array}$ & Precursor ion & Product ion & $\begin{array}{c}\text { Abundance } \\
(\%)\end{array}$ & $\begin{array}{l}\text { Error } \\
(\mathbf{m D a})\end{array}$ & Formula \\
\hline & & & & & 72.0811 & 10 & -0.2 & $\mathrm{C}_{4} \mathrm{H}_{10} \mathrm{~N}$ \\
\hline \multirow[t]{11}{*}{ M10 } & 294.1707 & 0.2 & $\mathrm{C}_{16} \mathrm{H}_{24} \mathrm{NO}_{4}$ & 294 & 276.1600 & 4 & 0 & $\mathrm{C}_{16} \mathrm{H}_{22} \mathrm{NO}_{3}$ \\
\hline & & & & & 251.1154 & 3 & -0.4 & $\mathrm{C}_{13} \mathrm{H}_{17} \mathrm{NO}_{4}$ \\
\hline & & & & & 248.1650 & 12 & -0.1 & $\mathrm{C}_{15} \mathrm{H}_{22} \mathrm{NO}_{2}$ \\
\hline & & & & & 207.1023 & 30 & 0.2 & $\mathrm{C}_{12} \mathrm{H}_{15} \mathrm{O}_{3}$ \\
\hline & & & & & 175.0759 & 78 & 0 & $\mathrm{C}_{11} \mathrm{H}_{11} \mathrm{O}_{2}$ \\
\hline & & & & & 151.0395 & 36 & 0 & $\mathrm{C}_{8} \mathrm{H}_{7} \mathrm{O}_{3}$ \\
\hline & & & & & 142.1229 & 65 & -0.3 & $\mathrm{C}_{8} \mathrm{H}_{16} \mathrm{NO}$ \\
\hline & & & & & 137.0602 & 24 & -0.1 & $\mathrm{C}_{8} \mathrm{H}_{9} \mathrm{O}_{2}$ \\
\hline & & & & & 100.0759 & 4 & -0.3 & $\mathrm{C} 5 \mathrm{H} 10 \mathrm{NO}$ \\
\hline & & & & & 88.0761 & 21 & -0.1 & $\mathrm{C} 4 \mathrm{H} 10 \mathrm{NO}$ \\
\hline & & & & & 70.0654 & 4 & -0.3 & $\mathrm{C} 4 \mathrm{H} 8 \mathrm{~N}$ \\
\hline
\end{tabular}




\section{FIGURES}




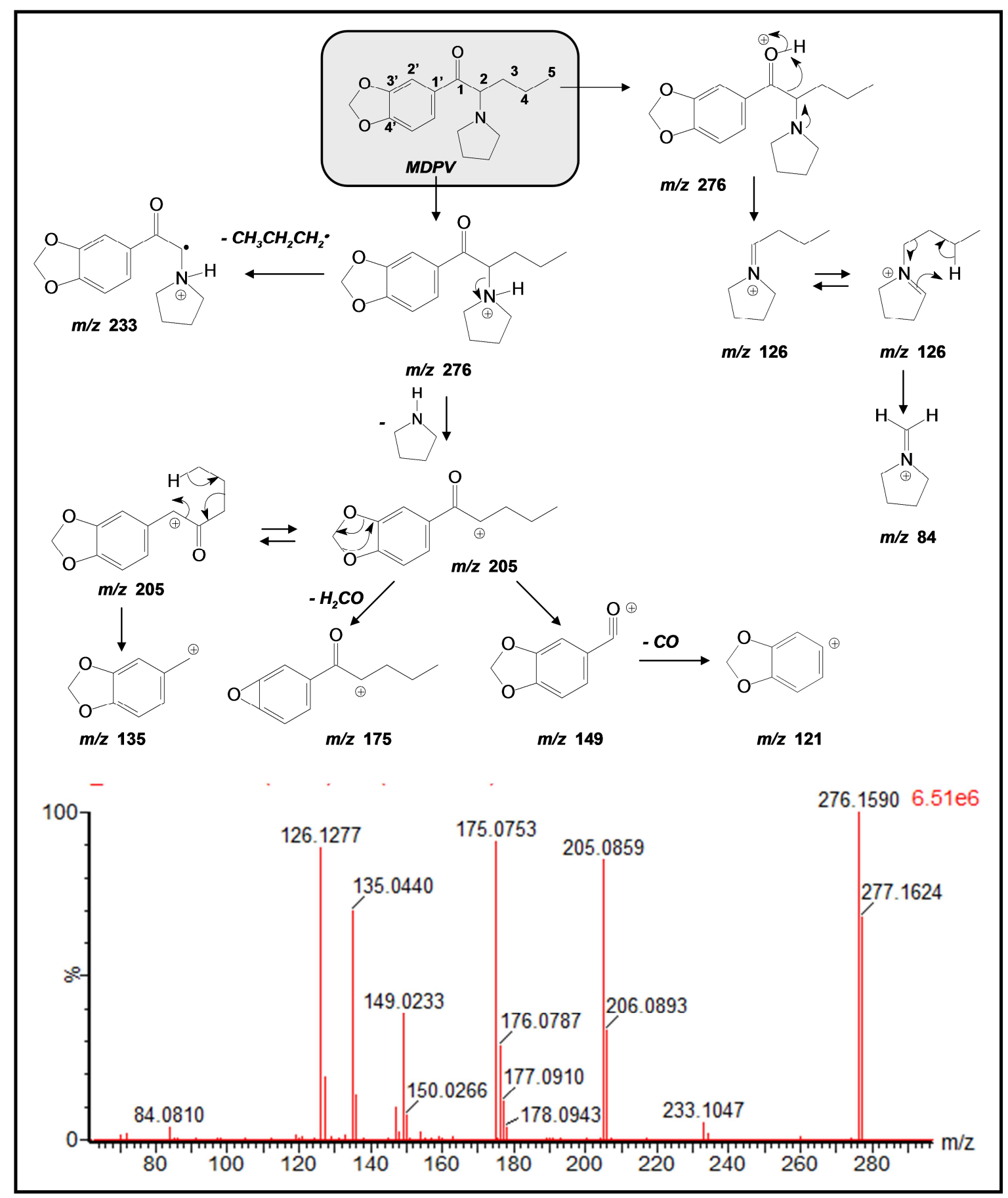

Fig 1 


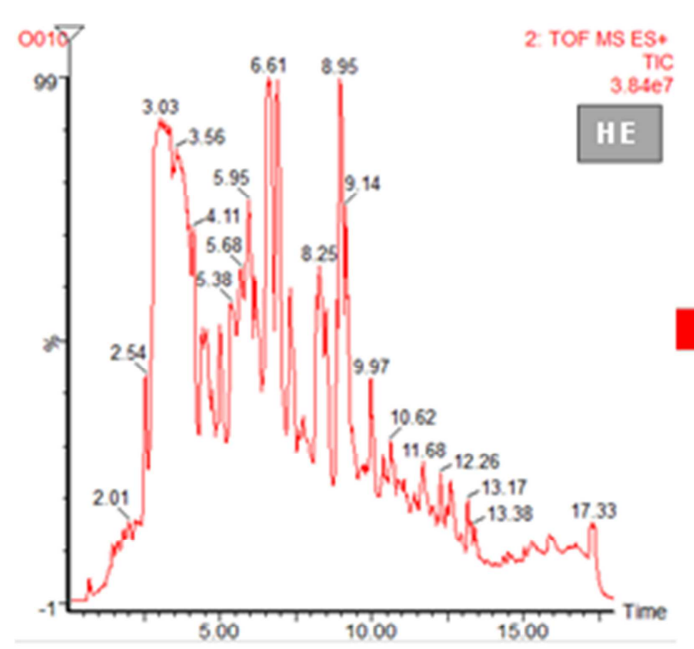

(a2)

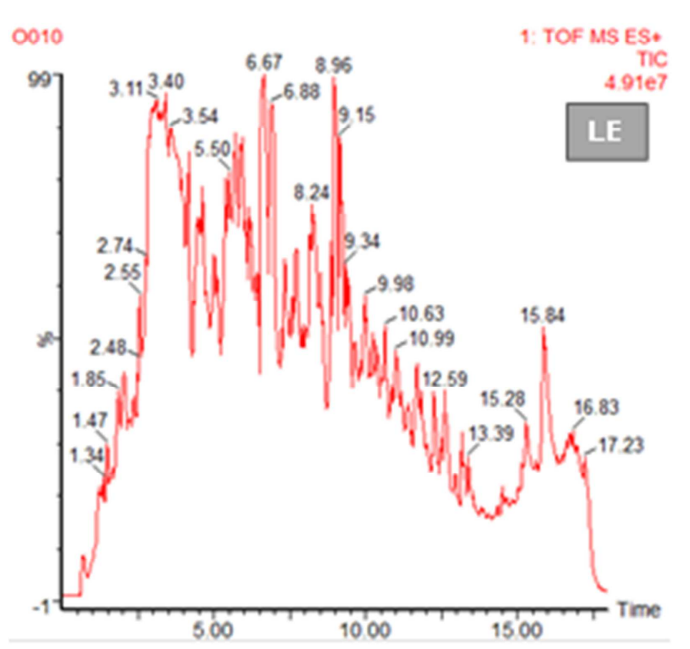

(a1)

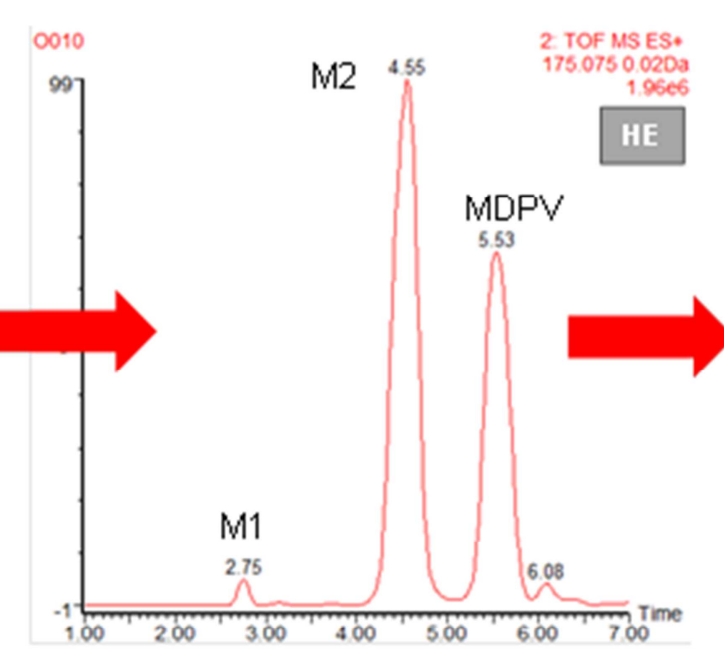

(b)

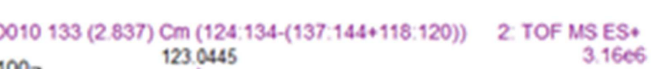

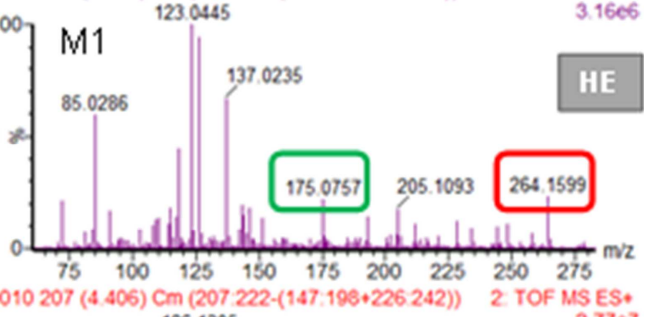

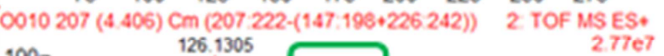

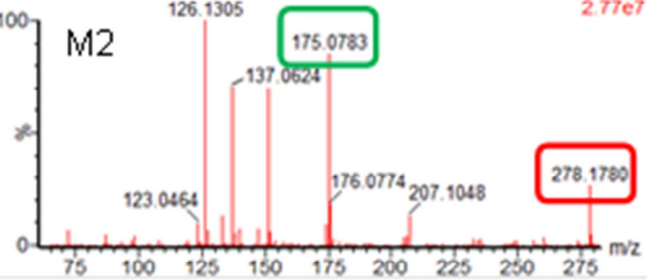

(c)

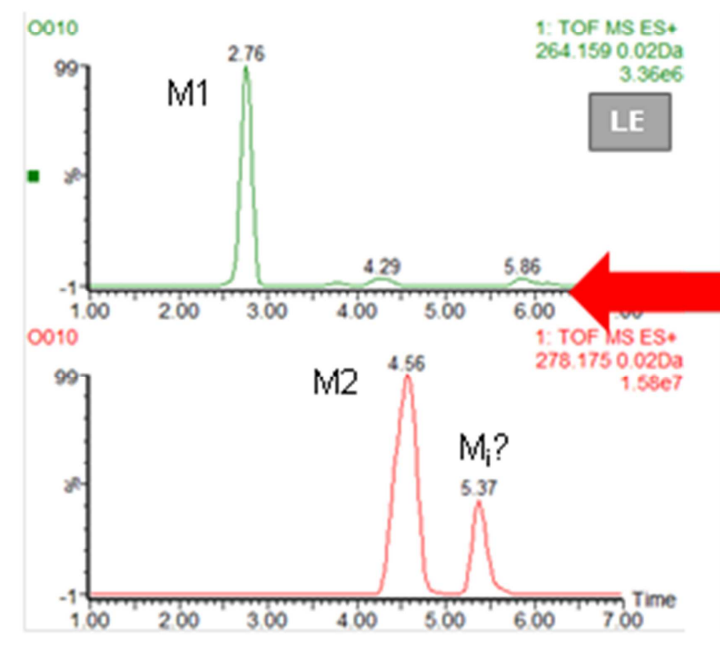

(e)

Fig 2 


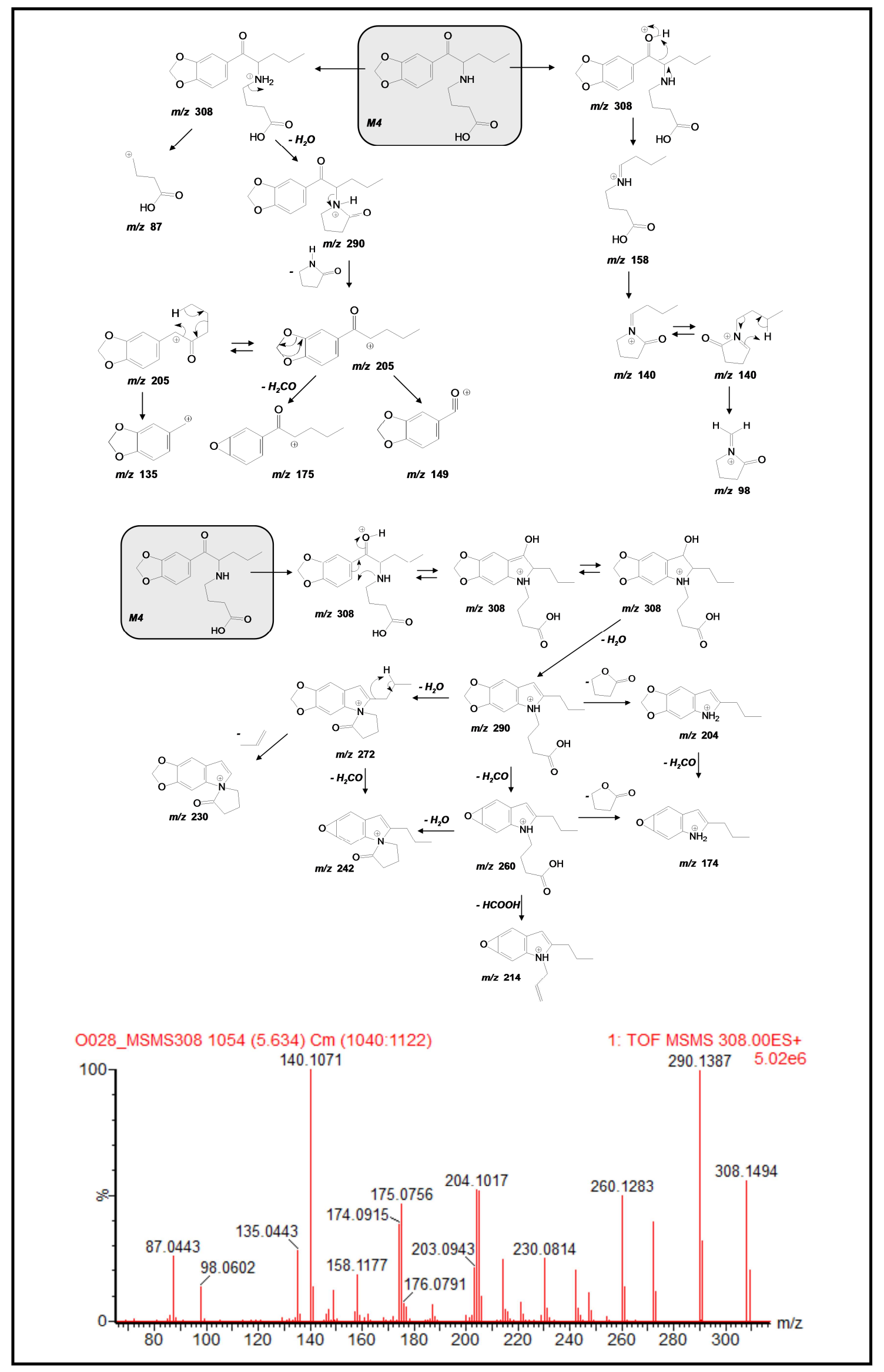

11

Fig 3 

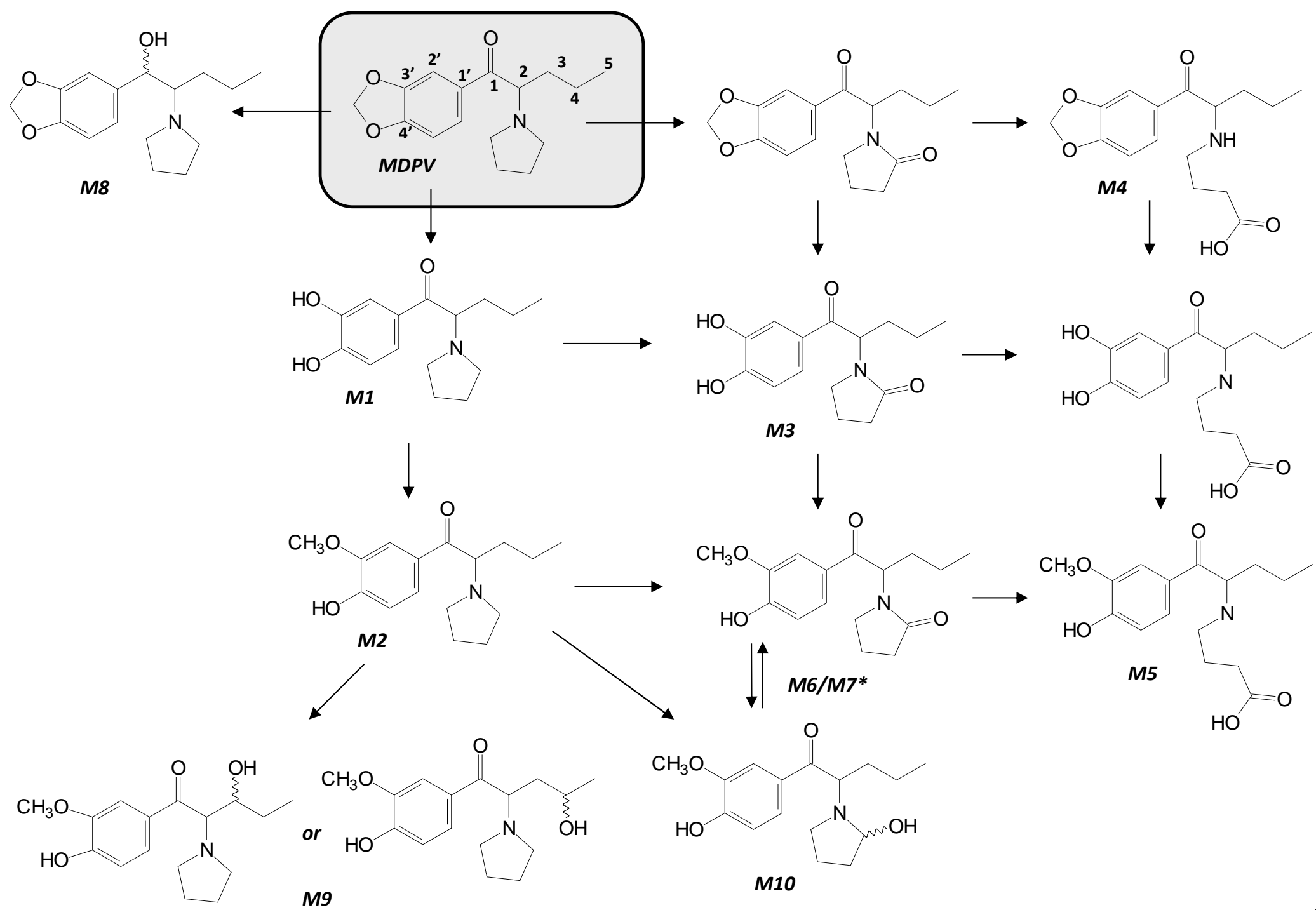